\title{
Taxonomy of the Neisseriae: Fatty Acid Analysis, Aminopeptidase Activity, and Pigment Extraction
}

\author{
CAROLYN HOKE AND NEYLAN A. VEDROS \\ Naval Biosciences Laboratory, School of Public Health, University of California, Berkeley, California 94720
}

\begin{abstract}
The cellular fatty acids of reference strains of most of the currently recognized species of Neisseria and Branhamella species were examined. Analysis of fatty acids with chain lengths of over 12 carbons supported the division of the species into two groups. Group I, comprised of $N$. meningitidis, $N$. gonorrhoeae, $N$. flava, $N$. subflava, $N$. perflava, $N$. sicca, $N$. mucosa, $N$. lactamica, and $N$. cinerea, contains methyl laurate, methyl palmitoleate, methyl palmitate, methyl oleate, and, often, methyl myristate as principal fatty acids. Group II, represented by $N$. caviae, $N$. cuniculi, $N$. ovis, and $B$. catarrhalis, contains large amounts of a 17-carbon fatty acid with a retention time similar to those of methyl-14, methyl hexadecanoate, methyl heptadecanoate, and, often, methyl stearate in addition to those fatty acids found in group I organisms. The greatest distinction between the two groups was the percentage of major fatty acids with chain lengths greater than 16 carbons. Aminopeptidase activity was most useful in differentiating $N$. meningitidis from $N$. gonorrhoeae. $N$. cuniculi, $N$. ovis, $N$. caviae, and $B$. catarrhalis had similar aminopeptidase reactions. Pigment profiles were of limited taxonomic value but were useful in differentiating between selected pigmented species.
\end{abstract}

Bacterial fatty acids, particularly those of longer chain length $\left(C_{12}\right.$ to $\left.C_{22}\right)$, have been shown to reflect relatedness among species similar to that shown by deoxyribonucleic acid (DNA) homology and transformation (7). Within the genera Neisseria and Branhamella, two distinct groups have been reported on the basis of fatty acid profiles: $N$. canis, $N$. subflava, $N$. flava, N. sicca, N. perflava, N. flavescens, $N$. mucosa, and one strain of $N$. cinerea in one group, and $B$. catarrhalis, $N$. caviae, $N$. ovis, and one strain of $N$. cinere $a$ in another group (8). The first group had a fatty acid composition almost identical with that previously found for $N$. gonorrhoeae and $N$. meningitidis $(9,10)$. A separate study (7) divided selected species into "true" neisseriae ( $N$. gonorrhoeae, $N$. meningitidis, $N$. cinerea, $N$. flavescens, and $N$. elongata) and "false" neisseriae (B. catarrhalis, $N$. ovis, and N. caviae).

Comparison of reported data is difficult because the fatty acid content of bacteria is markedly affected by nutritional and environmental factors (11). The present study examines the cellular fatty acids of reference strains of most Neisseria and Branhamella species under uniform growth conditions. Pigment profiles and aminopeptidase activity were included as additional tests to determine their usefulness as taxonomic tools.

\section{MATERIALS AND METHODS}

Bacterial strains. The strains used in this study were those previously reported (5).

Fatty acid extraction and analysis. Freeze-dried culture stocks were rehydrated, inoculated on GC agar base plates (Difco Laboratories), and incubated for 17 to $20 \mathrm{~h}$ at $36^{\circ} \mathrm{C}$ ( 5 to $10 \% \mathrm{CO}_{2}$, humidity). Harvested cells (approximately $10^{7}$ cells per ml) were inoculated into GC broth (Difco) and incubated for exactly $18 \mathrm{~h}$ on a rotary shaker (New Brunswick Scientific Co.) at $36^{\circ} \mathrm{C}$ (air, $200 \mathrm{rpm}$ ). The same batch of GC broth was used in all experiments. To eliminate contamination with agar and to enhance growth, the more fastidious gonococci were inoculated onto GC broth which had been added to an inert, nontoxic bottom layer of solidified resin (R. Giard, personal communication). The cells of all cultures were harvested by centrifugation $(7,000 \times g, 15 \mathrm{~min})$, washed twice with Hanks balanced salt solution ( $\mathrm{pH} 7.2$ ), and freeze-dried.

Cellular fatty acids were extracted by a modification of the procedure recommended by Supelco, Inc. (12). Freeze-dried cells $(100 \mathrm{mg})$ were mixed with $5 \mathrm{ml}$ of $5 \% \mathrm{NaOH}$ in $50 \%$ aqueous methanol (Lipo-Pure; Applied Science Laboratories, State College, Pa.) in tubes sealed with Teflon-lined caps. The cells were saponified for $30 \mathrm{~min}$ at $100^{\circ} \mathrm{C}$. After the product of saponification was cooled, its $\mathrm{pH}$ was lowered to 2.0 with $6 \mathrm{~N} \mathrm{HCl}$. The methyl esters of the free fatty acids were formed by adding $5 \mathrm{ml}$ of 10 to $12 \%$ (wt/vol) boron trichloride-methanol reagent (Applied Science Laboratories) and heating at $80^{\circ} \mathrm{C}$ for $5 \mathrm{~min}$. The methyl esters were extracted twice from the cooled mixture with $10 \mathrm{ml}$ of chloroform-hexane (1:4). A few 
drops of saturated $\mathrm{NaCl}$ solution were added to enhance separation. The solvent layers containing the fatty acids were combined and evaporated on a rotary evaporator (vacuum) to $0.2 \mathrm{ml}$. A small amount of $\mathrm{MgSO}_{4}$ was added to remove moisture, and the methyl esters were analyzed by gas-liquid chromatography within $1 \mathrm{~h}$. If not analyzed within $1 \mathrm{~h}$, the sample was flushed with $\mathrm{N}_{2}$ and stored at $-20^{\circ} \mathrm{C}$ for not more than 30 days before testing.

Gas-liquid chromatography. A Varian aerograph (2700) gas chromatograph (Varian Aerography Corp., Walnut Creek, Calif.) equipped with a flame ionization detector (adjusted to a sensitivity of $4 \times 10^{-10}$ to $8 \times$ $10^{-10}$ ) was used in all determinations. The coiled glass columns ( $6 \mathrm{ft}$ by $2 \mathrm{~mm}$ inner diameter) were packed with 3\% SP2100 DOH on 100/200 Supelcoport (Supelco, Inc., Bellefonte, $\mathrm{Pa}$.). Routine conditions of analysis were: detector, $275^{\circ} \mathrm{C}$; injector, $190^{\circ} \mathrm{C}$; oven, 150 to $225^{\circ} \mathrm{C}$ at $4^{\circ} \mathrm{C}$ per min and held at this temperature for $10 \mathrm{~min}$; and carrier gas (helium) at a flow rate of $20 \mathrm{ml} / \mathrm{min}$. The bacterial sample size was $2 \mu \mathrm{l}$; it was $1 \mu \mathrm{l}$ for the standard. The retention times of the test samples were compared with those of the standards (Supelco, Inc.) run daily. Standards and test samples were also cochromatographed to corroborate peak identity. Peaks that could not be identified were labeled " $X$ " and were listed by their retention time relative to known major fatty acid peaks. Peaks present in reagent blanks were disregarded in bacterial samples. Major peaks were those contributing to at least $3 \%$ of the total peak area, whereas those contributing to less than $3 \%$ were reported as trace amounts. The reproducibility of the method was determined with $N$. gonorrhoeae and $N$. meningitidis fatty acids $\mathrm{C}_{12}$ to $\mathrm{C}_{18}$. The standard deviation of the mean in seven repeat runs ranged from \pm 0.1 to \pm 1.43 .

Aminopeptidase activity. Aminopeptidase activities were determined by a modification of the procedure described by D'Amato et al. (3). Growth from 18-h-old cultures on GC agar (Difco; 5 to $10 \% \mathrm{CO}_{2}, 37^{\circ} \mathrm{C}$ ) was suspended in normal saline to a concentration of approximately $9 \times 10^{8}$ colony-forming units per $\mathrm{ml}$.

Chromogenic substrates were solubilized in a small volume of $50 \%$ ethanol except for $N$ - $\gamma$-glutamyl- $\beta$ naphthylamide, which was solubilized in $1 \mathrm{~N} \mathrm{NaOH}$. Each substrate was then diluted to $0.004 \mathrm{M}$ (final concentration) in $0.1 \mathrm{M}$ tris(hydroxymethyl)aminomethane-hydrochloride buffer to attain the following $\mathrm{pH}$ values: $N$ - $\gamma$-glutamyl- $\beta$-naphthylamide (Sigma Chemical Co.), pH 7.6; L-hydroxyproline- $\beta$-naphthylamide (ICN Nutritional Biochemicals), pH 7.2; Lseryl- $\beta$-naphthylamide (Sigma), $\mathrm{pH} 7.2$; glycyl-glycyl$\beta$-naphthylamide $(\mathrm{ICN}), \mathrm{pH} 8.0$; and $\mathrm{L}$-arginine- $\beta$ naphthylamide (Sigma), pH 8.0). A 40- $\mu$ l sample of each substrate was dispensed into plastic microtiter wells (Linbro of the Pacific, Los Angeles, Calif.). Forty microliters of bacterial suspension was added to the appropriate wells and incubated for $1 \mathrm{~h}$ in a humid chamber $\left(37^{\circ} \mathrm{C}\right)$. After incubation, $25 \mu \mathrm{l}$ of reagent $\mathrm{A}$ was added (reagent $\mathrm{A}: 2.0 \mathrm{M}$ tris(hydroxymethyl)aminomethane-hydrochloride buffer containing $0.35 \mathrm{M}$ sodium dodecyl sulfate) followed by $25 \mu$ of reagent B (3.0 g of fast blue BB [Sigma] per liter of methoxyethanol). Color was allowed to develop for $15 \mathrm{~min}$, and positive reactions were compared with controls consisting of microorganisms and test reagents only.

Pigment extraction. A modification of the technique of Ellinghausen and Pelczar (4) was used for pigment extraction. Strains were grown overnight on MuellerHinton agar, harvested, inoculated into two $250-\mathrm{ml}$ flasks of Trypticase soy broth (BBL Microbiology Systems), and incubated for 18 to $22 \mathrm{~h}\left(37^{\circ} \mathrm{C}\right)$ on a rotary shaker $(200 \mathrm{rpm}$; New Brunswick Scientific Co.). $N$. gonorrhoeae cultures were grown in similar volumes of Trypticase soy broth modified with $1 \%$ supplement and in the biphasic flasks described above. All cells were harvested by centrifugation and were washed twice with cold $1 \mathrm{~N}$ saline and once with $70 \%$ aqueous acetone. The cell sediment was weighed and suspended in methanol $(1 \mathrm{~g} / 50 \mathrm{ml}$ of methanol). The mixture was boiled for 5 min (under a reflux condenser), cooled, and held in the dark at $4^{\circ} \mathrm{C}$ for 2 to $18 \mathrm{~h}$. The supernatant was examined immediately in a Carey 219 scanning spectrophotometer (Varian Associates, Palo Alto, Calif.) or held at $4^{\circ} \mathrm{C}$ in the dark for up to 5 days before being tested. The wavelengths ( 200 to 500 $\mu \mathrm{m})$ were scanned at a rate of $1.0 \mu \mathrm{m} / \mathrm{s}$ with a slit width of $0.5 \mu \mathrm{m}$.

\section{RESULTS}

Fatty acid analysis. The percentage compositions of the fatty acids from the 16 species examined are shown in Table 1 . The principal fatty acids found were methyl laurate $(12: 0)$, methyl myristate $(14: 0)$, methyl palmitoleate (16:1), methyl palmitate (16:0), a fatty acid with a retention time similar to that of methyl-14, methyl hexadecanoate and heptadecanoate $(\alpha-$ $17: 0 ; 17: 1)$, methyl oleate (18:1), and methyl stearate (18:0). An unidentified compound, X-8, with a retention time of 1.23 relative to $18: 0$ was detected in $B$. catarrhalis, and methyl heptadecanoate $(17: 0)$ was present in significant amounts in $N$. ovis. The species could be divided into two groups with respect to the predominant chain lengths of the major fatty acids (Table 2). Group I was comprised of those organisms in which less than $30 \%$ of their major fatty acids had chain lengths greater than 16 carbon atoms. Group II consisted of those organisms in which over $60 \%$ of their major fatty acids had chain lengths greater than 16 carbon atoms. The latter appears due largely to the lower ratio of $C_{16}$ to $\mathrm{C}_{18}$ fatty acids. The ranges of these fatty acid ratios and the distinct division into two groups are shown in Table 3.

Aminopeptidase activity. The aminopeptidase activity with various chromogenic substrates is shown in Table 4. Considerable heterogeneity can be noted among strains within species, e.g., $N$. perflava and $N$. sicca. However, when activity with the substrate $N$ - $\gamma$-glutamyl $\beta$-naphthylamide was examined with 13 strains of $N$. gonorrhoeae and 17 strains of $N$. meningitidis (representing all known serogroups), a clear distinction was noted, in agreement with the observation of others (2). Although a limited number of strains was examined, it was of interest that $N$. ovis, $N$. cavicae, $N$. cuniculi, 


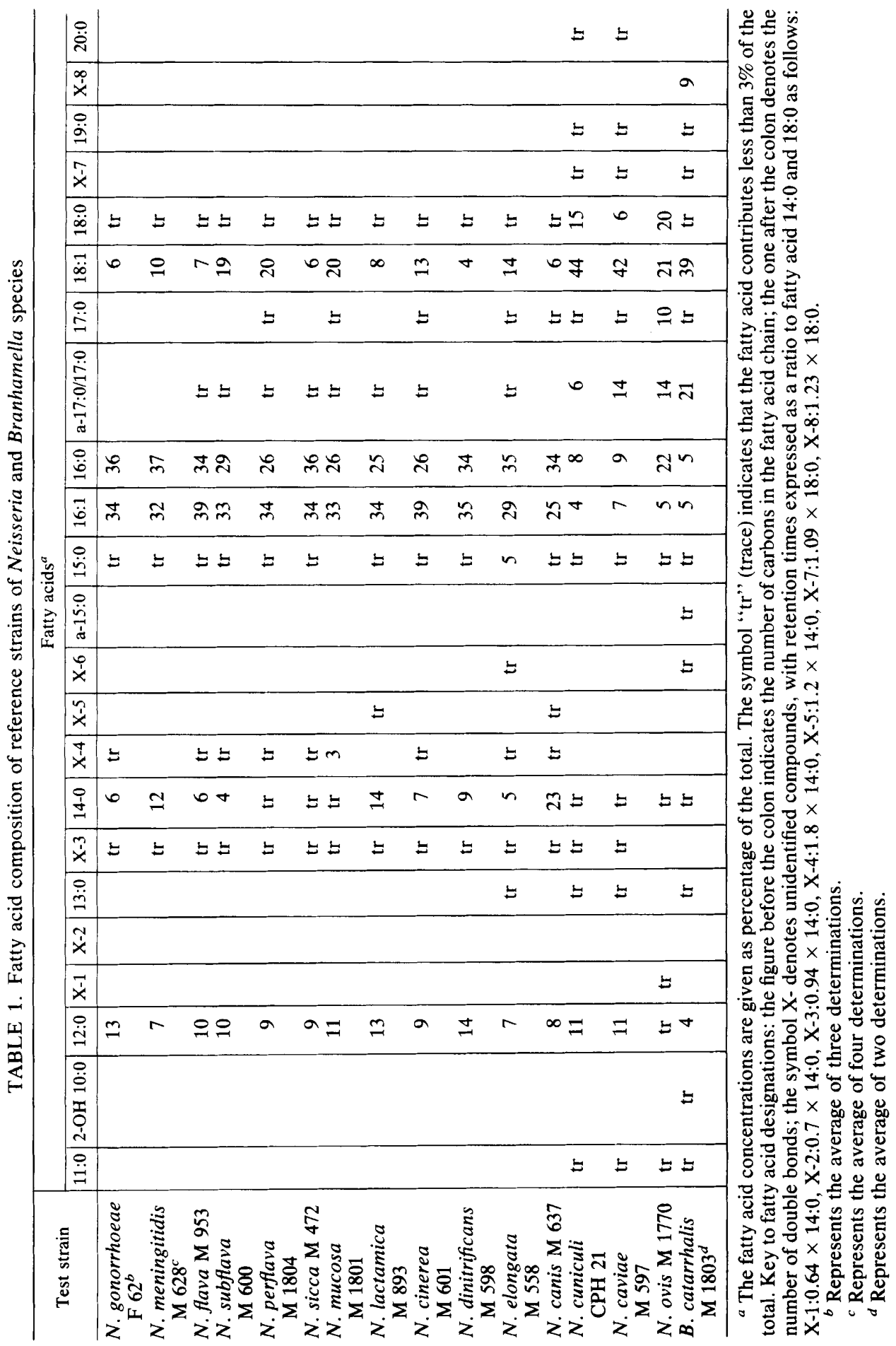


TABLE 2. Percentage of major fatty acids with chain lengths over 16 atoms occurring in reference strains of Neisseria and Branhamella species

\begin{tabular}{|c|c|}
\hline Test strain & $\begin{array}{l}\% \text { of major } \\
\text { fatty acids }\end{array}$ \\
\hline \multicolumn{2}{|c|}{ GROUP I ${ }^{a}$} \\
\hline N. gonorrhoeae F 62 & 6.0 \\
\hline N. meningitidis M 628 & 10.0 \\
\hline N. perflava M 1804 & 22.6 \\
\hline N. sicca M 472 & 6.7 \\
\hline N. subflava M 600 & 20.1 \\
\hline N. flava M 953 & 7.4 \\
\hline N. mucosa M 1801 & 21.7 \\
\hline N. lactamica M 893 & 8.7 \\
\hline N. cinerea M 601 & 13.9 \\
\hline N. denitrificans & 3.8 \\
\hline \multicolumn{2}{|c|}{ GROUP II ${ }^{a}$} \\
\hline N. caviae M 597 & 69.8 \\
\hline N. ovis M 1770 & 70.8 \\
\hline N. cuniculi CPH 21 & 74.6 \\
\hline B. catarrhalis M 1803 & 75.8 \\
\hline
\end{tabular}

${ }^{a}$ See text for description.

and $B$. catarrhalis demonstrated identical aminopeptidase profiles that were distinct from those of other Neisseria species studied.

Pigment profiles. Table 5 summarizes the absorption-peak profiles of methanol extracts of 14 species of Neisseria and Branhamella. It has been reported that the absorption peaks ( 265 to $270 \mu \mathrm{m})$ representing cellular protein, and those at 400 to $420 \mu \mathrm{m}$, reportedly representing cytochrome structures (1), appear to have no taxonomic significance. However, when the presence or absence of peaks between 300 and 400 $\mu \mathrm{m}$ (several xanthophylls [4] was examined, the species could be grouped into one of three absorption profiles. Profile I was characterized by absorption peaks at 265 to $270 \mu \mathrm{m}$ and 398 to $400 \mu \mathrm{m}$ (the latter often present in small amounts). This group consisted of species whose cells are nonpigmented on GC agar under standard conditions and appear as a rosy-colored sediment in a broth culture wash. Profiles II and III consist of species whose cells are yellow on GC agar and appear as a yelloworange sediment in a GC broth culture wash. It was of interest that, of the two strains of $N$. perflava examined (M 1804 and Ne 16), strain M 1804 exhibited no visible yellow pigment whereas strain $\mathrm{Ne} 16$ was bright yellow. This observation was reflected in the pigment profiles, and it agrees with previous studies (4) which indicated the presence of pigmented and nonpigmented members of the same species.

\section{DISCUSSION}

The results of the analyses of fatty acids reported here essentially support the observa- tions of others (6-8), in which species were assigned to two distinct groups. There were, however, minor differences under the growth conditions used in this study: e.g., $N$. cinerea belonged to group I and $N$. cuniculi belonged to group II; $N$. lactamica and $N$. denitrificans had fatty acid profiles consistent with those of other group I species. In this study the differences between the groups were best evaluated by comparing the species on the basis of fatty acids with chain lengths greater than 16 carbon atoms. The 3-OH-12:0 and 3-OH-14:0 fatty acids have been reported to be major fatty acids in some neisseriae (7). In this study, the retention time of $\mathrm{X}-3$ was almost indistinguishable from that of 3 $\mathrm{OH}-12: 0$, but $\mathrm{X}-3$ was present in only trace amounts. No 3-OH-14:0 was detected among the strains examined in this study. In contrast to the use of DNA base pairs, DNA hybridization, and intergenic transformation, it appears that fatty acid profiles are best applied to the taxonomy of Neisseria and Branhamella at the genus rather than the species level. The data do, however, lend support to the recommendation that the neisseriae contain methyl laurate, methyl palmitate, methyl oleate, and often methyl myristate as their principal fatty acids, with the majority of fatty acids occurring in chain lengths of less than 16 carbons; Branhamella and N. ovis, N. cunic$u l i$, and $N$. caviae contain, in addition to the principal fatty acids listed above for Neisseria, large amounts of methyl-14, methyl hexadecanoate, or methyl heptadecanoate, and often methyl stearate, with the majority of fatty acids occurring in chain lengths greater than 16 carbons.

Aminopeptidase may be of potential taxonomic value as more strains are examined. In this

TABLE 3. Range of fatty acid ratios occurring in groups of reference strains of Neisseria and Branhamella species

\begin{tabular}{|c|c|c|c|c|c|c|c|c|c|c|c|}
\hline \multirow{2}{*}{ Group } & \multicolumn{11}{|c|}{$\mathrm{C}_{16}$ fatty acids $/ \mathrm{C}_{18}$ fatty acids ${ }^{a}$} \\
\hline & 0 & 2 & 4 & 6 & 8 & 10 & 12 & 14 & 16 & 18 & 20 \\
\hline$I^{b}$ & & $L$ & & & & & & & & & \\
\hline $\mathrm{II}^{c}$ & $\sqcup$ & & & & & & & & & & \\
\hline
\end{tabular}

${ }^{a}$ The ratio between $(16: 0+16: 1)$ and $(18: 0+18: 1)$ major fatty acids; quantities of these fatty acids present in trace amounts ( $<3 \%$ of total fatty acids) are not included.

${ }^{b}$ The microorganisms comprising group I are $N$. gonorrhoeae $\mathrm{F} 62, N$. meningitidis $\mathrm{M} 628, N$. perflava M 1804, $N$. sicca M 472, $N$. subflava M 600, $N$. flava M 953, $N$. mucosa M 1801, $N$. lactamica M 893, $N$. cinerea $\mathrm{M} 601, N$. denitrificans $\mathrm{M} 598, N$. elongata $\mathrm{M}$ 1558 , and $N$. canis $\mathrm{M} 637$.

${ }^{c}$ The microorganisms comprising group II are $N$. ovis M 1770, $N$. cuniculi $\mathrm{CPH} 21, B$. catarrhalis $\mathrm{M}$ 1803 , and N. caviae M 597. 
TABLE 4. Summary of aminopeptidase activities of Neisseria and Branhamella strains

\begin{tabular}{|c|c|c|c|c|c|c|}
\hline \multirow[b]{2}{*}{ Test organism } & \multirow{2}{*}{$\begin{array}{l}\text { No. of strains } \\
\text { examined }\end{array}$} & \multicolumn{5}{|c|}{ Enzyme activity ${ }^{a}$} \\
\hline & & $\begin{array}{c}\gamma \text {-Glutamyl } \\
\text { aminopeptidase }\end{array}$ & $\begin{array}{l}\text { Hydroxyproline } \\
\text { aminopeptidase }\end{array}$ & $\begin{array}{c}\text { Arginine } \\
\text { aminopeptidase }\end{array}$ & $\begin{array}{c}\text { Serine } \\
\text { aminopeptidase }\end{array}$ & $\begin{array}{l}\text { Glycyl-glycine } \\
\text { aminopeptidase }\end{array}$ \\
\hline N. gonorrhoeae & 13 & 0 & 100 & 100 & 100 & 100 \\
\hline N. meningitidis & 17 & 100 & 47 & 100 & 41 & 94 \\
\hline N. subflava & 1 & 0 & 100 & 100 & 100 & 100 \\
\hline N. flava & 1 & 0 & 100 & 100 & 100 & 100 \\
\hline N. perflava & 14 & 36 & 100 & 100 & 93 & 100 \\
\hline N. sicca & 7 & 14 & 86 & 100 & 86 & 100 \\
\hline N. flavescens & 1 & 0 & 100 & 100 & 100 & 100 \\
\hline N. mucosa & 3 & 67 & 100 & 100 & 100 & 100 \\
\hline N. canis & 1 & 0 & 100 & 100 & 100 & 100 \\
\hline N. cuniculi & 1 & 0 & 0 & 100 & 100 & 100 \\
\hline N. cinerea & 1 & 0 & 100 & 100 & 100 & 100 \\
\hline N. dinitrificans & 1 & 0 & 0 & 100 & 0 & 100 \\
\hline N. ovis & 1 & 0 & 0 & 100 & 100 & 0 \\
\hline N. elongata & 1 & 0 & 100 & 100 & 100 & 100 \\
\hline N. catarrhalis & 3 & 0 & 0 & 100 & 100 & 100 \\
\hline N. lactamica & 2 & 0 & 100 & 100 & 100 & 100 \\
\hline N. caviae & 1 & 0 & 0 & 100 & 100 & 100 \\
\hline
\end{tabular}

${ }^{a}$ Numbers are percentages of strains giving a positive reaction.

study, and others (2), detection of $\gamma$-glutamyl aminopeptidase was a consistent trait with strains of $N$. meningitidis and $N$. gonorrhoeae. This may be important in those clinical laboratories where differentiation between these two closely related pathogens may be difficult when the standard biochemical tests are used. With other species, heterogeneity was evident when several strains were examined. The one reference strain of $N$. denitrificans and several

TABLE 5. Principal-pigment profiles of Neisseria and Branhamella reference strains

\begin{tabular}{|c|c|}
\hline Absorption peaks at: & Strain \\
\hline $265-270,398-400^{a} \mu \mathrm{m}$ & $\begin{array}{l}\quad \text { GROUP I } \\
N . \text { gonorrhoeae F } 62^{b} \\
N . \text { meningitidis M } 628 \\
N . \text { subflava M } 600 \\
B . \text { catarrhalis M } 1803 \\
N . \text { caviae M } 597 \\
N . \text { cinerea M } 601 \\
N . \text { perflava M } 1804 \\
N . \text { cuniculi CPH } 21\end{array}$ \\
\hline $\begin{array}{c}265-270,337-340,355-357 \\
375-379,400-410^{a} \mu \mathrm{m}\end{array}$ & $\begin{array}{l}\quad \text { GROUP II } \\
\text { N. flava M } 953 \\
\text { N. perflava } \mathrm{Ne} 16 \\
\text { N. sicca } \mathrm{M} 472 \\
\text { N. mucosa } \text { CPH } 12\end{array}$ \\
\hline $\begin{array}{l}270,328-333,346-350, \\
\quad 376-379,400-418^{a} \mu \mathrm{m}\end{array}$ & \begin{tabular}{l}
\multicolumn{1}{c}{ GROUP III } \\
N. lactamica M 893 \\
N. canis $\mathrm{M} 637$
\end{tabular} \\
\hline
\end{tabular}

${ }^{a}$ This peak was often present in trace amounts.

${ }^{b}$ This strain did not demonstrate an absorption peak at $398-400 \mu \mathrm{m}$. strains of $N$. meningitidis were the only strains negative for glycyl-glycine aminopeptidase. Furthermore, reference strains of $N$. cuniculi, $N$. ovis, $N$. caviae, and $B$. catarrhalis had similar aminopeptidase activity. If these results are consistent as more strains are examined, then this characteristic may be of potential value in classifying these closely related species.

Pigment profiles of Neisseria and Branhamella species also appear, with the reference strains examined, to be of limited taxonomic value. Their contribution may be their sensitivity in detecting small quantities of pigment in visually nonpigmented isolates and in differentiating between selected pigmented species. Pigment extraction and known pigment profiles may help quantitate what is otherwise very often a qualitative evaluation.

The data in this and in our previous report (5) support the use of DNA base pairs, DNA hybridization, intergenic transformation, and cellular fatty acids as taxonomic tools in characterizing the neisseriae and the branhamellae. Although the fatty acid analysis in this study was capable of dividing members of the genera Neisseria and Branhamella into only two groups, the genetic data in our previous report (5) suggested that the neisseriae and branhamellae should be divided into three genera, forming a new genus intermediate between Neisseria and Branhamella. Although it is our opinion that fatty acid analysis should be considered of lower weight than genetic studies in determining taxonomic relationships, we believe that fatty acid analysis, in conjunction with genetic techniques, can be a valuable tool for establishing taxonomic rank 
within the family Neisseriaceae. Analyses of other strains are in progress. The genetic and biochemical techniques used in this study are currently being applied to several aerobic, gramnegative cocci which were "atypical" in their biochemical reactions and could not be readily identified.

\section{ACKNOWLEDGMENTS}

We thank Harold Guard for assistance with the fatty acid analyses, Nancy Olson for assistance in pigment extract analyses, and Ron Giard for technical assistance.

We thank the Office of Naval Research and Grossman Endowment Fund for financial support.

\section{REPRINT REQUESTS}

Address reprint requests to: Dr. Neylan A. Vedros, School of Public Health, University of California, Berkeley, CA 94720 .

\section{LITERATURE CITED}

1. Berger, U. 1961. Untersuchungen ueber die Pigmentbildung durch Neisseria. Z. Hyg. 147:461-469

2. Bøvre, K., and E. Holten. 1970. Neisseria elongata sp. nov., a rod-shaped member of the genus Neisseria. Reevaluation of cell shape as a criterion in classification. J. Gen. Microbiol, 60:67-75

3. D'Amato, R. F., L. A. Eriquez, K. M. Tomfohrde, and E. Singerman. 1978. Rapid identification of Neisseria gonor- rhoea and Neisseria meningitidis by using enzymatic profiles. J. Clin. Microbiol. 7:77-81.

4. Ellingshausen, H. C., Jr., and M. J. Pelczar. 1955. Spectrophotometric characterization of Neisseria pigments. J. Bacteriol. 70:448-453.

5. Hoke, C., and N. A. Vedros. 1982. Taxonomy of the neisseriae: deoxyribonucleic acid base composition, interspecific transformation, and deoxyribonucleic acid hybridization. Int. J. Syst. Bacteriol. 32:57-66.

6. Jantzen, E., K. Bryn, T. Bergan, and K. Bøvre. 1974. Gas chromatography of bacterial whole cell methanolysates. V. Fatty acid composition of neisseriae and moraxellae. Acta Pathol. Microbiol. Scand. Sect. B 82:767-779.

7. Jantzen, E., K. Bryn, and K. Bøvre. 1974. Gas chromatography of bacterial whole cell methanolysates. IV. A procedure for fractionation and identification of fatty acids and monosaccharides of cellular structures. Acta Pathol. Microbiol. Scand. Sect. B 82:753-766.

8. Lambert, M. A., D. G. Hollis, C. W. Moss, R. E. Weaver, and M. L. Thomas. 1971. Cellular fatty acids of nonpathogenic Neisseria. Can. J. Microbiol. 17:1491-1502.

9. Lewis, V. J., R. E. Weaver, and D. G. Hollis. 1968. Fatty acid composition of Neisseria species as determined by gas chromatography. J. Bacteriol. 96:1-5.

10. Moss, C. W., D. S. Kellogg, Jr., D. C. Farshy, M. A. Lambert, and J. D. Thayer. 1970. Cellular fatty acids of pathogenic Neisseria. J. Bacteriol. 104:63-68.

11. O'Leary, M. W. 1962. The fatty acids of bacteria. Bacteriol. Rev. 26:421-447

12. Supelco, Inc. 1977 . Identification of bacteria by analysis of cellular fatty acids. Bulletin 767. Supelco Inc., Bellefonte, $\mathrm{Pa}$. 